\title{
In the Pursuit of Practical Solutions and "Satisficing" Performance: The Case of Israel's Nonprofit Human Services
}

\author{
Rita Mano \\ Department of Human Services \\ Faculty of Welfare and Health Sciences \\ University of Haifa
}

Received: May 14, 2019 Accepted: June 3, 2019 Online published: June 27, 2019

doi:10.5296/jpag.v9i2.14982ＵRL: https://doi.org/10.5296/jpag.v9i2.14982

\begin{abstract}
Evaluating performance in nonprofit human services remains an ongoing empirical and conceptual challenge. Here, we introduce the concept of "satisficing" to capture the influence of intra- and inter- organizational factors on performance. We contend that the combination of organizational age and size, which shapes an organization's complexity and dependency, will define the balance between social and economic criteria. Further, we contend that this definition will ultimately enable nonprofit human services to reach a satisficing level of management practices. More importantly, we contend that a practical compromise between social and economic performance determines whether satisficing performance is possible though practical solutions so that both effective attainment of the organizational mission and efficient management practices are possible with little risk of goal displacement.
\end{abstract}

\section{Israel's Nonprofit Human Services}

Nonprofit sector activity in Israel constitutes $1.4 \%$ of the state's GDP, placing the country second to the USA (Schnid et al. 2008). Israel's NPOs operate with public funding provided by the state to support and ensure the quality and reliability of human services. Nevertheless, Israel's NPOs have been under growing pressure to adopt accountable and efficient management practices (Carlson et al., 2010). This pressure led to a dilemma between two contradictory trends: On the one hand, Israel's NPOs needed to become more effective, i.e., to increase the quality and span of the human services they provided. On the other hand, the NPOs had to adhere to efficient management practices, i.e., to use economic resources in ways that are efficient and cost effective (Mano, 2015; Schmid \& Bar-Almog, 2016). 
The economic crisis of 2018 increased this dilemma because Israel's NPOs experienced ambiguity regarding the best way to assess performance and avoid the risk of closing down services. While their main concern was economic performance, they were also apprehensive about the risk of goal displacement and of neglecting their social performance. In view of the challenge to increase the importance of organizational efficiency whilst maintaining the organizational mission, the notions of efficiency and effectiveness became competitive values (Coupet, 2018; Wadongo \& Abdel-Kader, 2014). These competing forces necessitated consideration of the role played by the NPOs' internal as well as external environment (Radiah \& Norli, 2014). Not surprisingly, NPOs sought practical solutions to reach a compromise between the internal and external environment (Lecy, Schmitz \& Swedlund, 2012; Baruch \& Ramalho, 2006). A significant part of this process necessitated making practical compromises in terms of either economic or social performance (Coupet \& Haynie, 2018). We refer to this point of compromise as satisficing performance (March \& Simon, 1958).

In the remainder of the present study, we present a set of propositions to unravel how internal and external factors lead to the formulation of a satisficing level of performance in NPOs. We illustrate these stages with Figures 1-2 depicting (a) the relationship among organizational context, complexity and dependency (Figure 1) and (b) the relationship among complexity, dependency and social and economic performance (Figure 2) affecting the level of satisficing performance.

\section{The Internal Environment}

\subsection{NPO Complexity}

Traditional organizational theory asserts that organizations emerge, develop and survive in response to their organizational environment (Pfeffer \& Salancik, 1978). The interface between organizational activities and task environment defines the structure of an organization (Pugh \& Hickson, 1976). Appropriate structures in NPOs increase the odds for practices oriented to best results (Herman \& Renz, 2008), leading to higher sustainability (Golden, Longhofer, \& Winchester, 2009). First, organizational structures harbor constraints that impede full exploitation of managerial skills in facilitating organizational processes (Mano, 2015). Second, a good structure is one that provides a high degree of "fit" between environmental pressures and internal processes, thus increasing the odds of effectiveness and best-result-oriented practices (Herman \& Renz, 2008) and providing higher leverage for organizational sustainability (Liket et al., 2014; Golden, Longhofer, \& Winchester, 2009). The successful application of these structures finds expression in organizational complexity (Chikoto \& Halicki, 2013).

Complexity is evident when the interrelation between the internal and external components of NPOs necessitates considering the interactions between separate organizational elements and assesses their coordination (Fabak, 2010). Complexity has several dimensions (Chikoto \& Halicki; 2013). The first is organizational age: Older organizations have a greater level of legitimacy, whereas younger organizations on the way to self-establishment do not have a wide network for collaboration (Coupet \& Haynie, 2018). In contrast, older organizations 
cannot easily change their missions or provide different goods/services or processes (Child \& Gronberg, 2007) and are less likely to renew strategies, making them prone to crisis (Mano, 2010; 2015). The second dimension is organizational size: Large organizations are more institutionalized and stable. Because of their size, they can recruit more resources and are able to attract support from non-government sources because they are (a) reliable providers of services (Schmid, Bar \& Nirel, 2008) and (b) less prone to crisis (Balser \& McKlusky, 2005; Ramanath, 2009). Large organizations are therefore more likely to maintain structures that enable them to successfully detect and cope with environmental threats (e.g., Mano, 2010).

The majority of NPOs in Israel are large and old institutions, and capable of raising public support and accessing resources and hence able to develop a strong strategy and organizational culture (Ramanath, 2009). These NPOs are therefore better able to cope with economic and political changes in funding (Herman \& Renz, 2008; Mano, 2015; Balser \& McKlusky, 2005; Ramanath, 2009). At the same time, these complex NPOs exhibit higher compliance with accounting, regulations and efficient resource management (Pajunen, 2006; Verbruggen et al., 2011). Not surprisingly, these complex NPOs prefer to use "proven" management and exhibit higher resistance to change but lack innovation a functionality in management (Ramanath, 2009; Schmid et al., 2008). (Verbruggen et al., 2011). By contrast, younger and smaller NPOs are in a weaker institutional position (Golden et al., 2009) and are more likely to seek novel and untested areas of social activity with little concern about efficient outcomes (Libby et al., 2017), mainly due to their low dependence on public stakeholders. In such NPOs marked by lower complexity, the potential to address issues of financial hardship proactively is limited. Nevertheless, they can respond to changes in work processes effectively and hence are better able to cope with turbulent environments (Mano, 2010).

\section{The External Environment}

\subsection{NPO Dependency on Stakeholders}

Complexity variables point to the importance of dependency on stakeholders and indicate that NPOs become larger and older over time, mostly due to heavy state funding. This is perhaps the most common type of NPOs in Israel, especially in the wake of changes in social policy that promoted the outsourcing of human services to the nonprofit sector (Schmid \& Almog-Bar, 2016). Prominent performance assessment studies indicate that stakeholders on the individual or group level affect the flow of resources and have a direct or indirect influence on management decision-making (Rowley, 1997). Indeed, following cuts in public funding (Mano, 2011) it became clear that for the great majority of Israeli NPOs, coping with the challenges of managing stakeholder expectations affects management practices. This is particularly evident since different stakeholders represent different interests and seek to attain different purposes (Carnochan et al., 2014; Calabrese, 2013; Liket et al., 2014). Yet more important than the particular effect of stakeholder density and centrality is their combined effect (Abzug \& Webb, 1999). Low density and enable NPOs to manage themselves independently. Yet when stakeholders are defined in terms of high density and high centrality, NPOs are likely to be less autonomous (Schmid et al, 2008; Ramanath, 2009). This is the 
point at which NPOs focus on the constraints and advantages of their relationship to public and private stakeholders (Schmidt \& Bar-Alon, 2016) and become preoccupied with searching for the best possible way to reach practical compromises (Lecy et al., 2012; Mano, 2011).

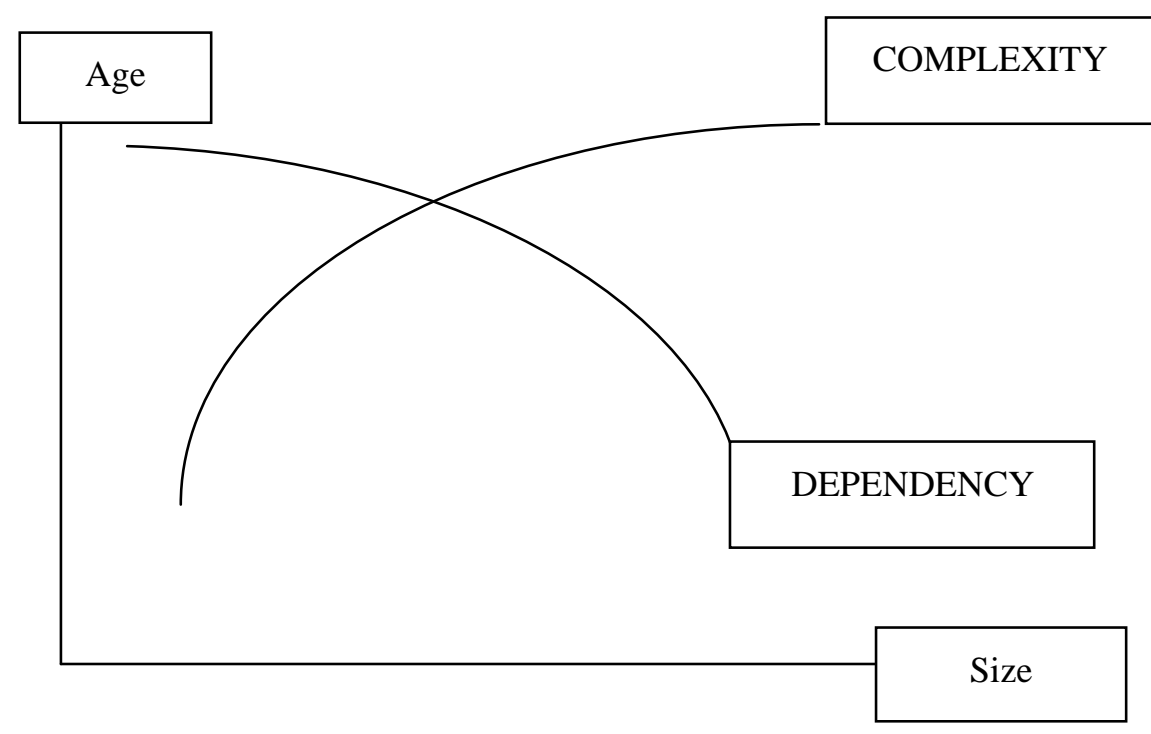

Figure 1. Organizational context effects on complexity and dependency

\section{Satisficing Performance}

Organizational performance reflects the degree to which human services attain social impact (Costa et al., 2011) but NPO performance remains a challenge when both social and economic performance are evaluated. Social performance ensures that social goals are pursued effectively (Mano, 2014) and is vital to ensure organizational legitimacy and continuous social support (Camarero \& Garrido, 2009). Economic performance ensures the appropriate management of economic resources (Calışkan \& Callon, 2010; Charnes et al., Seiford, 2013). The efficient use of resources increases the odds of controlling environmental uncertainty and the ability to deliver sustainable human services over long periods of time (O'Toole \& Meier, 2011; McWilliams et al., 2016). We refer to this adequate tradeoff and practical compromise between social and economic criteria or performance as satisficing performance.

Satisficing performance emerges then when NPOs reach financial performance without overlooking attainment of social goals or when economic goals do not prevent the attainment of social goals (Mano, 2014). Yet, satisficing performance manifested differently in different NPOs. A satisficing level of performance dictates that NPOs maintain good functioning in the internal environment. That is, they must maintain an optimal balance between complexity and low dependency (Carnochan et al., 2014). Stronger-e.g., older and larger-NPOs may prefer a tradeoff between social and economic performance that is less satisficing yet more economically suitable to the requirements of high demand stakeholders (Baruch \& Ramalho, 2006). Optimizing the functioning of the internal environment increases the odds for social support and legitimacy because the institutional environment and its stakeholders expect 


\section{Macrothink}

NPOs to be efficient in their management practices (Mano, 2011). We thus can postulate that satisficing performance emerges as a practical compromise that enables NPOs in Israel characterized by complexity that is adequate but not too high to exhibit higher flexibility toward stakeholders, with little risk to their autonomy and social support (Lecy et al., 2012; LeRoux \& Wrigth, 2010).

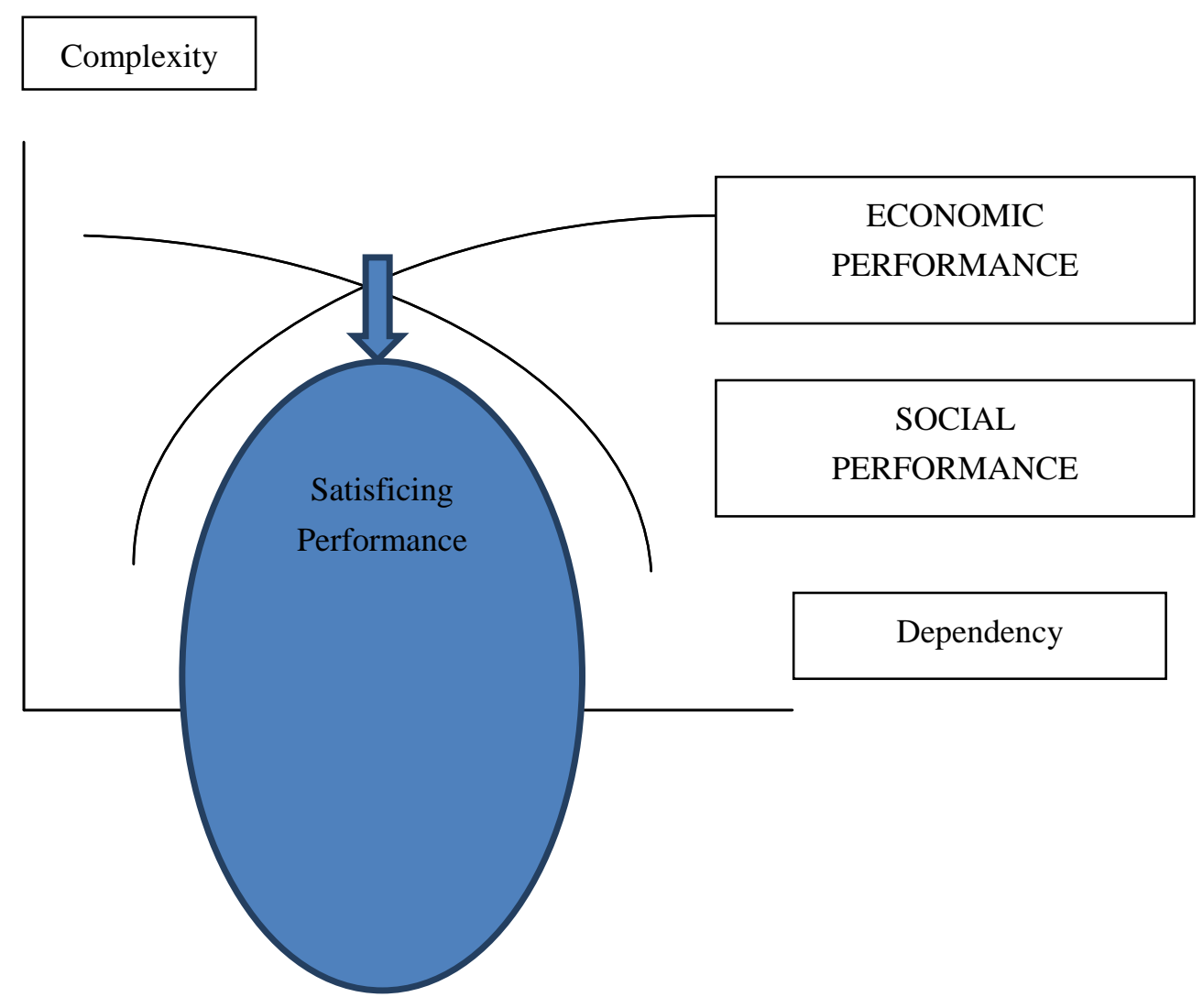

Figure 2. Predicting "satisifcing" performance

\section{Discussion}

The management of NPOs in Israel is a delicate process that has become extremely challenging in the wake of cuts in government funding and the global economic crisis. In order to ensure that NPOS maintain sustainable social outcome Israel's NPOs adopted compromising management practices to define performance and prevent crisis over time. They had to balance between social performance and effective attainment of their mission on the one hand and economic performance and efficient resource utilization on the other. Compromise and performance reevaluation were vital to survival. Nevertheless, this compromise had to consider points of disagreement between the internal and external environment and adopt a satisficing level of performance.

In the present study, we formulated a set of propositions to address the conceptual link between internal and external factors that affect performance in NPOs. We addressed the theoretical and practical importance of complexity, dependency and social and economic 
performance. We then set out to show how the interplay between dependency and complexity defines the balance between social and economic performance. We showed that satisficing performance is the outcome of complex navigation between stakeholders' expectations and demands and in the short run manifests itself in a practical compromise between economic and social performance criteria (Mano, 2014). The proposed model illuminates the importance of practical compromises in turbulent economic times and fluctuating funding conditions. This is especially relevant when such changes are rapid and often difficult to tap into at the opportune time since the normative environment has a slow and often delayed effect on organizational behavior. By assessing the interplay between internal and external environment factors operating in Israel's NPOs, we can estimate how these factors are conducive to achieving a satisficing level of performance.

The proposed conceptual approach has important implications therefore, for decision-making in NPOs. It enables managers to draw upon a theoretical organizational framework to handle concerns about performance issues. This conceptual framework makes it easier to account for the quick and unexpected changes imposed by stakeholders and offers much promise regarding practical solutions to environmental changes. Looking for practical compromises to achieve and maintain satisficing performance has the potential to forge greater commitment among NPOs managers and board members, in the long run. NPOs can forge strong alliances that facilitate agreements regarding economic and social goals and prevent the occurrence of a gradual goal displacement process when NPOs' vision shifts away from initial institutionalized and official goals and toward efficient day-to day-operations.

A significant first step involves determining the relevance of economic and social performance criteria (Mano, 2014) and combining social and technical goals (Calabrese, 2013). Second, NPOs should address the advantages and obstacles associated with organizational size and age (Pugh \& Hickson, 1976; Mano, 2014; Chikoto \& Halicki, 2013; Carnochan, Samples, Myers \& Austin; 2014). Third, they must define the level of dependency on public funds (Mano, 2010; Mitchell \& Calabrese, 2018) to avoid the risks of goal displacement whilst keeping their sources of funding intact (Garrow \& Hasenfeld; 2014). Yet variations in levels of satisficing performance may emerge in different NPOs, depending on their level of social support and legitimacy. Considering that flexible organizations cope better with environmental pressure and more easily adjust to changing situations, we postulated that when both complexity and dependency are sufficiently high but not at the maximum level, NPOs are more likely to reach an ideal balance at which they achieve stable organizational processes but remain relatively independent. We therefore postulate that satisficing performance emerges when organizations maintain an adequate but not maximum level of complexity and exhibit higher flexibility toward stakeholders, with little risk to their autonomy and social support.

\section{Recommendation for Practice}

To fit the economic demands of high demand stakeholders, stronger NPOs may prefer a tradeoff between social and economic performance that is satisficing. This is presumably not a typical tradeoff between social and economic goals, but rather a balancing act accomplished 
by emphasizing one or the other relative to specific activities and/or changes over time (Baruch \& Ramalho, 2006). Managers eager to increase performance and sustain operations in NPOs should be careful when defining the level of "satisficing" because the price of doing so may affect the attainment of social goals and jeopardize organizational legitimacy.

\section{References}

Abzug, R., \& Webb, N. J. (1999). Relationships between nonprofit and for-profit organizations: A stakeholder perspective. Nonprofit and Voluntary Sector Quarterly, 28(4), 416-431. https://doi.org/10.1177/0899764099284003

Balser, D., \& McClusky, J. (2005). Managing stakeholder relationships and non profit organization effectiveness. Nonprofit Management and Leadership, 15(3), 295-315. https://doi.org/10.1002/nml.70

Baruch, Y., \& Ramalho, N. (2006). Communalities and distinctions in the measurement of organizational performance and effectiveness across for-profit and nonprofit sectors. Nonprofit and Voluntary Sector Quarterly, 53, 456-501. https://doi.org/10.1177/0899764005282468

Calabrese, T. (2013). Running on Empty: The Operating Reserves of U.S. Nonprofit Organizations. Nonprofit Management and Leadership, 23(3), 281-302. https://doi.org/10.1002/nml.21064

Camarero, C., \& Garrido, M. (2009). Improving museums performance through custodial, sales and customer orientations. Nonprofit and Voluntary Sector Quarterly, 38(5), 847-867. https://doi.org/10.1177/0899764008319230

Carlson, J., Kelley, A. S., \& Smith, K. (2010). Government performance reforms and nonprofit human services: 20 Years in Oregon. Nonprofit and Voluntary Sector Quarterly, 39(4), 630-652. https://doi.org/10.1177/0899764009360824

Carnochan, S. M., Samples, M. M., \& Austin, M. (2014). Performance measurement challenges in nonprofit human service organizations Nonprofit and Voluntary Sector Quarterly, 43(6), 1014-1032. https://doi.org/10.1177/0899764013508009

Charnes, A., Cooper, W. W., Lewin, A. Y., \& Seiford, L. M. (Eds.). (2013). Data envelopment analysis: Theory, methodology, and applications. Springer Science \& Business Media.

Chikoto, G. L., \& Halicki, M. (2013). Contextual factors and negotiating spaces: exploring the emergence of nonprofit and hybrid voluntary organizations Nonprofit Management \& Leadership, 23(3), 34-62. https://doi.org/10.1002/nml.21065

Child, C. D., \& Grønbjerg, K. A. (2007). Nonprofit advocacy organizations: Their characteristics and activities. Social Science Quarterly, 88(1), 259-281. https://doi.org/10.1111/j.1540-6237.2007.00457.x

Costa, L. D. F., Oliveira Jr, O. N., Travieso, G., Rodrigues, F. A., Villas Boas, P. R., Antiqueira, L., \& Correa, R. L. E. (2011). Analyzing and modeling real-world phenomena 
with complex networks: a survey of applications. Advances in Physics, 60(3), 329-412. https://doi.org/10.1080/00018732.2011.572452

Coupet, J. (2018). Exploring the link between government funding and efficiency in nonprofit colleges. Nonprofit Management and Leadership, 29(1), 65-81. https://doi.org/10.1002/nml.21309

Coupet, J., \& Haynie, J. L. (2018). Toward a valid approach to nonprofit efficiency measurement. Nonprofit Management and Leadership, 1-22. https://doi.org/10.1002/nml.21336

Fabak, R. (2010). Complexity in organizations and environment - adaptive changes: An adaptive decision-making Interdisciplinary Description of Complex Systems, 8(1), 34-48.

Garrow, E. E., \& Hasenfeld, Y. (2014). Institutional logics, moral frames, and advocacy: explaining the purpose of advocacy among Nonprofit Human-Service organizations, Nonprofit and Voluntary Sector Quarterly, 43(1), 80-98. https://doi.org/10.1177/0899764012468061

Golden, S., Longhofer, W., \& Winchester, D. (2009). Nonprofits in need. Contexts, 8(3), 14-15. https://doi.org/10.1525/ctx.2009.8.3.14

Herman, R., \& Renz, D. (2008). Advancing nonprofit organizational effectiveness research and theory: Nine theses. Nonprofit Management and Leadership, 18(4), 399-415. https://doi.org/10.1002/nml.195

Lecy, J. D., Schmitz, H. P., \& Swedlund, H. (2012). Non-governmental and not-for-profit organizational effectiveness: A structured literature review. VOLUNTAS: International Journal of Voluntary Nonprofit Organizations, 23(2), 434-457. https://doi.org/10.1007/s11266-011-9204-6

LeRoux, K., \& Wright, N. (2010). Does performance measurement improve strategic decision making? Findings form a national survey of nonprofit social service agencies. Nonprofit \& Voluntary Sector Quarterly, 39(4), 571-587. https://doi.org/10.1177/0899764009359942

Libby, P. P., Deitrich, L., \& Mano, R. (2017). Lobbying practices in Israel's advocacy groups: An assessment of the Libby-Lobbying Model; In Mano, R. (Ed.) Nonprofit management in transition, Administrative Sciences, 3, 45-53.

Liket, K. M., Rey-Garcia, \& Maas, K. H. (2014). Why aren't evaluations working and what to do about it: A framework for negotiating meaningful evaluation innonprofits American Journal of Evaluation, 35(2), 171-188. https://doi.org/10.1177/1098214013517736

Mano, R. (2010). Organizational crisis, adaptation, and innovation in Israel's nonprofit organizations: A learning approach, Administration in Social Work, 34(4), 344-350. https://doi.org/10.1080/03643107.2010.500985

Mano, R. (2011). Predicting organizational development in Israel's nonprofit human services: 
the effects of organizational context, structure and geographic location, Journal of Health and Human Services Administration, 31, 27-37.

Mano, R. (2015). Complexity and Crisis in Human Services, LAP LAMBERT Academic Publishing, Saarbrücken, Germany ISBN 978-3-659-76000-6.

Mano, R. S. (2014). Social media and online health services: A Health Empowerment perspective to online health information. Computers in Human Behavior, 39, 404-412. https://doi.org/10.1016/j.chb.2014.07.032

March, J. G., \& Simon, H. A. (1958). Organizations. New York: John Wiley and Sons.

McWilliams, A., Parhankangas, A., Coupet, J., Welch, E., \& Barnum, D. T. (2016). Strategic decision making for the triple bottom line. Business Strategy and the Environment, 25(3), 193-204 .https://doi.org/10.1002/bse.1867

Mitchell, G. E., \& Calabrese, T. D. (2018). Proverbs of nonprofit financial management. The American Review of Public Administration. https://doi.org/10.1177/0275074018770458

O'Toole, Jr, L. J., \& Meier, K. J. (2011). Public management: Organizations, governance, and performance. Cambridge University Press .https://doi.org/10.1017/CBO9780511784040

Pajunen, K. (2006). Stakeholder influences in organizational survival. Journal of Management Studies, 43(6), 1261-1288. https://doi.org/10.1111/j.1467-6486.2006.00624.x

Pfeffer, J., \& Salancik, G. (1978). The external control of organizations: A resource dependent perspective. New York: Harper \& Row.

Pugh, D. S., \& Hickson, D. J. (1976). Organization structure in its context: The Aston program. Lexington, MA: Heath, Lexington Books.

Radiah, O., \& Norli, A. (2014). NPO, Internal controls, and supervision mechanisms in a developing country, VOLUNTAS: International Journal of Voluntary and Nonprofit Organizations, 25(1), 201-224. https://doi.org/10.1007/s11266-012-9335-4

Ramanath, R. (2009). Limits to institutional isomorphism. Examining internal processes in NGO- government interactions. Nonprofit and Voluntary Sector Quarterly, 38(1), 51-76. https://doi.org/10.1177/0899764008315181

Rowley, T. J. (1997). Moving beyond dyadic ties - A Network Theory of stakeholders ${ }^{\text {ee }}$ influences. Academy of Management Review, 22(4), 887 - 903. https://doi.org/10.5465/amr.1997.9711022107

Schmid, H., \& Almog-Bar, M. (2016). Correlates of trisectoral partnerships in the human services: Implications for policy and practice. Human Service Organizations: Management, Leadership \& Governance, 40, 189-192. https://doi.org/10.1080/23303131.2015.1117557

Schmid, H., Bar, M., \& Nirel, R. (2008). Advocacy activities in nonprofit human service organizations: Implications for policy. Nonprofit and Voluntary Sector Quarterly, 37(4), 581-603. https://doi.org/10.1177/0899764007312666 


\section{Macrothink}

Journal of Public Administration and Governance ISSN 2161-7104 2019, Vol. 9, No. 2

Verbruggen, S., Christiaens, J., \& Milis, K. (2011). Can resource dependence and coercive isomorphism explain nonprofit organizations' compliance with reporting standards? Nonprofit and Voluntary Sector Quarterly, 40(1), 5-32. https://doi.org/10.1177/0899764009355061

Wadongo, B. M., \& Magdy, A-K. (2014). Contingency theory, performance management and organizational effectiveness in the third sector, International Journal of Productivity and Performance Management, 63(6), 680 - 703. https://doi.org/10.1108/IJPPM-09-2013-0161

\section{Copyright Disclaimer}

Copyright for this article is retained by the author(s), with first publication rights granted to the journal.

This is an open-access article distributed under the terms and conditions of the Creative Commons Attribution license (http://creativecommons.org/licenses/by/4.0/). 